this method of detection carlier and more frequently. It puts it also within the means of every patient to obtain a competent histological report in any case in which there is the least suspicion of cancer whenever the situation of the disease renders this possible. It puts the patient, however poor, on an equal footing with his richer neighbour in the struggle against the disease. It is hoped, howerer, that in the case of those who can afford it a charge will be made, as while $I$ hold it to be the duty of public authorities to provide medical necessities for the poor, it is no part of their duty to provide medical luxuries for the rich

The third resolution is the following: "That your committee be authorized to publish monthly in the local press the following notice:

\section{"Borot'GH OF Portsmouth.}

"The only cure for cancer at present known is its early and complete removal. Cancer, if rem, e l early, has been prove conclusively to be a curable disease. If neglected, and no removed in its earliest stage, it is practically invariably fatal. The paramount importance of its early recognition and early removal is therefore evident. For this purpose the assistance both of the public and the medical profession is requisite, and a grave responsibility resis on buth. It is only by their mutual co-operation that the lavages of this terible, isease can be lessened. The following information should be 0 : vital assistance to the public. It is no exaggeration to $\mathrm{s} y$ uhat, if acted upon, the result would be the saving annually of many hundred of lives, which at present are inevitably lost.

"1. Cancer, in its early and curable stage, gives rise to no pain or symptoms of ill health whatever.

or symptoms of ill health whatever. in its early stage are conspicuously manifest. To wit tess:

3. In case of any swelling occurring in the breast of a woman after 40 years of age, a medical man should at once be consulted. A large proportion of such $s$ wellings are cancer.

"4. Any bleeding, however trivial, occurring after the change of life $n$ eans almost invariably cancer, and cancer which is then curable. If neglected till pain occurs, it means cancer wnich is almost always incurable.

"5. Any irregular bleeding occurring at the change of life should invariably be submitted to a doctor's investigation. It is not the natural method of the onset of the change of life, and in a large number of cases means commencing cancer.

"6. Any wart or sore occurring on the lower lip in a man after 45 years of ase is almost certainly cancer. If removed at onco thears is cortain if ule

the cure is certain, if neglected the result is inevitably fatal.

"7. Any sore or swelling occurring on the tongue or inside of the mouth in a man after 45 years of age should be submitted to investigation without a moment's delay, and the decision a once arrived at by an expert microscopical examination whether it is cancer or not. A very large proportion of such sores or swellings occurring at. this time of life are cancer, and if neglected for even a few. weeks the result is almost inevitably fatal. If removed at once the prospect of cure is good.

" 8. Any bleeding occurring from the bowel after 45 years of age, commonly supposell by the public to be " piles," should be submitled to investigation at once. A large proportion of such cases are cancer, which at this stage is perfectly curable.

“9. When warts, moles, or other growths on the skin are exposed to constant irritation they should be immediately removed. A large number of them, if neglected, terminate in cancer.

"10. Avoid irritation of the tongue and cheeks by broken, jagged teeth, and of the lower lip by clav pipes. Many of these iritations, if neglectel, terminate in cancer.

'11. It is desirable that rooms occupied by a pers:on suffering from cancer should be cleaned aud disinfected from time to time.'

This public notice may possibly give rise to some adverse criticism. The necessity for the widespread knowledge of some such facts as these before anything really hopeful can be done for cancer has been discussed above and need not be repeated. It will be noted that no attempt is made to deal at all exhaustively with the symptoms of caucer. It was felt that this would only confuse the public and serve no useful purpose. Just the commonest situations of the disease, and those in which its 1 res nce could hardly escape the notice of the victim and the commonest times at which it appears, have been emphasized.

I may say in conclusion that the Local Government Board was approached with the view of obtaining its consent to making cancer a notifiable disease, and I believe I am correct in saying that it has been approached from ot er quarters with a similar request. The idea was that it would make for the earlier detection of cancer, because if a medical man were attending a doubtful case and knew that if it was cancer, compulsory notification was required of him, it would be an inducement to him, should such inducement be necessary, to act on the second resolution and obtain a microscopical report, which is recognized as the only reliable criterion in early cancer.
The request to the Local Government Board was not acceded to. Government departments are notoriously conservative and difficult to move. Possibly, if the Board is similarly pressed from other quarters, it may be induced to reconsider its decision.

Whether the above means, adopted after due considera. tion, are the best for endeavouring to instruct the public in the early danger signals of cancer may be a matter of opinion; what is no matter of opinion at all is this, that unless and until some means are found of disseminating such knowledge, though there may be cures of cancer here and there, owing to accidentally favourable circumstances, these can only form the exceptions that go to prove the rule of its uniorm fatality, and that there can be no sensible reduction in its appalling mortality. This mortality amounted in the British isles for the fire years 1906-1910 to 939 per 1,000,000 for all persons.

\section{EXPERIENCES OF THE NATIONAL HEALTH INSURANCE ACT.:}

\section{By E. F. PRATT, M.D.}

Is approaching so highly contentious a subject as the Insurance Act one is confronted at the outset with a great difficulty; perhaps I should rather say a fear-a fear of exaggeration-for, whether one be a friend or opponent of the measure; one may be tempted to concentrate -one's mental vision more particularly on those experiences which more than others appear to support one's own views.

As it has fallen to my lot to have the honour of relating to you some of my experiences, I have endeavoured in the course of this short paper to give an absolutely impartial and unbiassed account of the working of the Act. I have also been at some pains to collect opinions from $\mathrm{my}$ colleagues, from insured persons themselves, and from friendly society officials.

'Twelve months ago I think a great many of us felt discouraged and downhearted, for we were then, owing to the precipitate haste with which the Act was introduced, in an almost chaotic condition. We were all surfeited with a heavy crop of rare fruit in the sliape of red cards; we were all feeling symptoms of incipient scrivener's palsy from signing those cards; we were exasperated by the wretchedly cumbersome day books, and the forefingers and thumbs of our right hands were in a chronic state of wourning through handling the carbon papers of the day book and prescription book. The discontent and discouragement, and the thirst for revenge on the introclucer of the Act continued more or less during the whole of the first quarter, but my conscience compels me to admit that that vengeful thirst was considerably allayed on A pril 16th with the arrival of our first cheque. We then began to think that there might be something in the Insurance Act after all. Although one felt inclined to do anything rather than bless the red-cards; they served a very useful purpose, as the following anecdote will shor.

An insured person, suffering from a bad cough, called one day to see a certain colleague of mine, who naturally asked to see the man's card. .The card was produced, and my colleague was surprised to read "E. F. Pratt" on the back of it. This was at once pointed out to the man, who, however, replied that he had had a bottle of medicine from Dr. Pratt, but, as it had done him no good, aud as he understood the Act allowed free choice of doctor, he thought he would try someone else. Now, had it not been for that little red card my colleague might have used up no end of brain cells in endeavouring to stop the cougl of a person for whom he would receive no payment.

The day bonks were, to put it mildly, simply awful, and it was very welcome news to most of us when we heard they were to be discontinued and their places taken by record cards. When the latter were introduced we welcomed them with open arms, and, following out a hint from a colleague, I commenced a numerical system, which I have found exceedingly easy to work. I ordered a stock of plain visiting cards, and each patient coming under

* A paper read at the winter scientific demonstration of the Newcastle-on-Tyne Division, British Medical Association, Fobruary 20tb. 
treatment has his record card numbered, and he himself is given one of the plain visiting cards with a corresponding number, as well as ny initials and the year written on it by me; for example, suppose a man called Archibald Campbell Mc'Tavish McPherson comes to consult me, I fill up the record card with his name and address and a number. I then fill up a visiting card with a corresponding number, my initials, and the year, and give it to him, at the same time explaining that I wish him to bring that card with him every time he comes during the remainder of the year. In this way I am able to pick ont the record card of every patient who comes to see me in a few seconds, and I am most particular, and I think rightly so, about cr ering up every consultation or visit, as the case may be.

The cards of those on the risiting list are also numbered on the first visit and lept all together in a place by themselves. Then, as each patient is removed from the visiting list, his card is put in its correct numerical position amongst the other cards of those persons who come to the surgery to consult me. I have had no difficulty with this system. In 99 per cent. of cases the person produces his number; the remaining 1 per cent.the forgetful ones-never fail either to make a special journey the next day to show me their number or else they send it to me through the post.

While on the subject of record cards, I should like to mention the matter of " occupation." It is really astonishing to find how difficult it is to get a correct answer to the question, What is your occupation? Only about a third of the patients seem to understand it; the great majority of the remainder tell me where they work-Armstrong's, Hawthorn's, etc., as the case may be. A ferv are under the impression I am asking them their religion, and one man, on my putting the question to him, replied that he was a Scotchman. I cannot say, but of course that may be an occupation of itself.

Has the Act in any way affected the self respect of the medical man? I think at first most of us felt that the work might be more or less degrading-degrading not through the kind of work done or the type of cases treated, but degrading inasmuch as what had been looked upon for years as the most unselfish and most self-denying of all occupations would now be nothing more nor less than a commercial undertaking. Let us take for granted that this be true. Is there, then, any shame in acting commercially so long as we do so honestly and uprightly? I think not; nor do I think for one moment that the Act has made the profession of medicine any the less unselfish or selfdenying. The hesitation we felt at first was really after all only sentimental, and what our grandfathers would have refused to contemplate we, in more modern times, under changed conditions, fighting for our very existence a Chancellor who, though "comparatively a poor man," has certainly shown pronounced commercial instincts-we I say, sinking our prejudices, executed a tactical retreat, and accepted the Act.

Now has this acceptance been justified by results? After a year's working we are able to think more calmly, the perspective is more correct, and the conclusions which we can draw are of much greater value than were our anticipations twelve months ago.

First of all as to the amout of work done. Here there can be no two opinions, for it is easy to prove that our work has increased enormously, and even such an eccentric person as Mr. Handel Booth will be compelled to admit, when he sees the figures, that we have worked, and worked hard, for every penny we have received. Here are some figures that may interest you. I have taken the last six months of 1913 as being a much better period for my purpose than the first six months of the year. From July lst to December 31st I paid visits and gave consultations to the large number of 3,665. My cheques for that period totalled approximately $£ 305$, so that I take it that for each visit or consultation I received the magnificent fee of.1s. 8d. Mr. Lloyd George said a few nights ago that the lawyers only wished they had such an opportunity of making money as the doctors. I find it quite easy to picture the expression on my lawyer's face if $I$ were to offer him 1s. 8d. for his advice. Still, we must not forget that this money is certain and that we have no drugs to pay for. The certainty of payment is very consoling, and when I find that my ledgers contain $£ 4,000$ of bad debts which have accumulated since I commenced practice twenty years ago, I ask myself whether it is better to book an uncertain $2 \mathrm{~s} .6 \mathrm{~d}$. or work for a safe $1 \mathrm{s.} 8 \mathrm{~d}$.

In the same speech Mr. Lloyd George made the remark that by the Insurance Act he had given an average yearly income of something over $\$ 200$ to every man on the panel. He quite forgot-it is wonderful how convenient a memory can be-to tell his audience how much each man was losing through private patients becoming insured persons. In a mixed practice like mine, if we suppose that my income from the panel amounts to $£ 500$, then I should be quite within the mark by saying that I am losing $£ 300$ a year, making a net increase of only $\$ 200$. That is to say, if, before the panel, I was receiving $£ 300$ a year, or $£ 150$ a half-year, from persons who are now insured, now $I$ am receiving $£ 500$ a year, or $£ 250$ a half-year. But think what this means. Before the Act, for $£ 150$ I would make visits or hold consultations to the number of 1,200 -that is, reckoning a minimum of 2s. 6d. a time. Now, taking as a basis the figures I have already given of work done, I find that with a panel bringing me in $£ 250$ in six months I should have paid visits or held consultations to the number of 3,000 , reckoning 1 s. $8 d$. as the pay for each visit or consultation; but as I was previously receiving $£ 150$ for the 1,200 visits, it follows that I am now only receiving $£ 100$ extra for 1,800 visits, which works out at 1s. 1d. a time. Even if we allow for medicines supp'ied you will see that there is still a very large margin of difference. It does not require a very mathematical brain to see that the increase of work is ont of all proportion to the increase of income. Up to the present moment the Chancellor has not apologized.

It is natural, then, that we should feel it galling sometimes to have to attend people as panel patients who are quite in a position to pay bills as prirate patients, and $I$ think it is a pity that some scheme has not yet been adopted to allow of the fixing of a wage limit.

Out of these 3,665 visits and consultations I have been able to gather some interesting data.

With regerd to diseases, the respiratory tract claims first place:

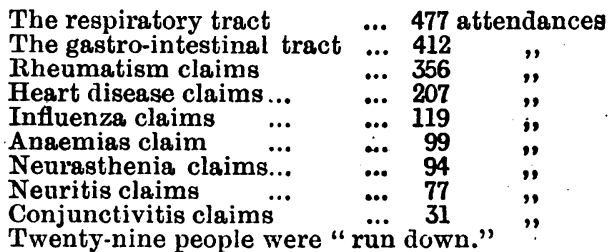

The remainder of the attendances were for a long list of miscellaneous ailments, including migraines, whitlows, boils, carbuncles, and wounds and fractures.

I find the greatest number of attendances I paid on any one patient during the six months was 91 (and this patient was previously a good paying patient of fifteen years' standing), and the smallest number was 1 .

Dividing the patients into sexes, I find that-

$$
\begin{array}{llll}
\text { Men and boys received } & \ldots & \ldots & 2,778 \text { visits } \\
\text { Women and girls received } & \ldots & 887 \text {, }
\end{array}
$$

or in the proportion of three to one.

I remember a year ago my colleagues and $I$ were all hoping we should get very few women on our panels, as we fully expected to find that the women and girls would require so much more attention than the men and boys. The figures I have just given show that my fears were groundless. The proportion of males to females on my list is exactly the same as the proportion of those nnder treatment, namely, three to one. Altogether, out of a mean average of 1,866 on $\mathrm{my}$ panel during the last six months of 1913, persons to the number of 751 were under treatment, an average of rather less than five attendances each. Of these, 567 were males and 184 females, that is, as I have already stated, in the proportion of three to one. So we have a curious coincidence, namely:

Proportion of males to females on my

$$
\begin{aligned}
& \text { panel... } \ldots \text {......... } \\
& \text { Proportion of visits to males as compared } \\
& \text { with visits to females... ... ... } 3 \text { to } 1 \\
& \text { Proportion of males under treatment } \dddot{\text { to }} \\
& \text { females under treatment } \ldots . . .3 \text { to } 1
\end{aligned}
$$

while in the whole of the United Kingdom the proportion of insured males to insured females is 2.4 to 1 . 
In discussing the ages my tables are. unfortunately not complete, as I have found it impossible to get eren the average age of my panel list.

However, I can give you, dividing the ages into quin. quennial periods, the percentage of attendances each period received.

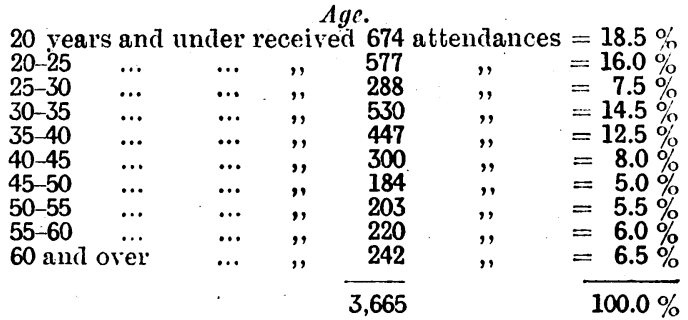

What effect, if any, has the Act had on the morals of the insured person? In all classes of society in al countries there is alrrays a certain section of the com munity the members of which believe in getting all they can with as little outlay as possible, and to those people the Insurance Act has been a great temptation. First of all there is the case of the member of a friendly society who prior to the Act was drawing 10s. to 12s. a week sick benefit. Such a man, especially if he were married, would think twice before staying off work. But give this man an additional 10s. weekly, an additional sick benefit which we must remember is due to him, and for which he does not forget he has paid by a compulsory deduction from his wages, and he will only think once about attempting to get a certificate from his doctor, so that he too may enjoy some of that refreshing fruit that had been so freely promised him.

Then, again, there is the case of the woman who earns as a charwoman or day-girl $3 \mathrm{~s}$. 6 d. to $5 \mathrm{~s}$. a week. Can we blame such a person who, feeling a bad cold coming on, elects to stay at home and be comfortably nursed, knowing that she can draw as sick pay a sum equal to double her wages? In these days of servant famine, too, she is not scared by the bogey of losing lier situation, for, if she lose the one, she will find dozens of people ready to give her another,

I think that an amendment of the Act whereby the amount of sick pay would be limited to a certain proportion of the wages is imperative. At any rate $I$ am sure that such an amendment would greatly diminish the number of claimants on the sick list of the approved societies.

I do not always blame the girls, for my experience teaches me that the mistresses themselves are sometime at fault. One mistress actually expected me to give her cook a sick certificate because she (the mistress) was going away. for a fortnight's holiday, and wanted to lock up the house. She said she thought her cook was run down, and that a fortnight's rest with sick pay would do her good. I asked her if she would have thought of sending her cook away in this manner if she (the mistress) had been staying at home. She replied: "Ob, no! I couldn't do without my cook"! Needless to say. I refused a certificate, pointing out to her that it was customary only to give a certificate of necessity and not of convenience.

Another female patient came to me last November and said she was run down and would like a certificate, as she thought a month's rest would do her good. After telling her that I also would like a month's rest, I asked her if she could undertake some work for the following week if necessary. She replied that she could, as she was then ont of employment. Of course I refused the certificate.

I quote these two cases as instances of the difficulty which men on the panel meet, and I am absolutely certain that the blackguarding to which we have been exposed time and time again at the meetings of various friendly and trade societies has been quite undeserved. In this district, at any rate, the medical men have all done their best to discover and prevent malingering, and I have no reason to think that the rest of the country as a whole would show any difference.

Quite a goodly number of persons have asked for sick certificates only to be refused by me, and perhaps I am not astonished to hear that I have gained the reputation of being a hard man. In spite of this I was agreeably sur- prised to find that only one person liad taken advantage of the December option and had transferred to another panel. This shows that people generally do still have respect for an honest opinion. In the case of the one patient who left me, if my diagnosis were incorrect I deserved to lose her ; on the other hand, if I were right then I was better of without her.

Of cases of cold calculating malingcring I have liad none. At the beginning the red flag of malingering was waved so frantically and frequently before our fases that one got into the habit of looking with suspicion on every patient who turned up, but I believe that a great many cases of so-called malingering are the products solely of the super-suspicious minds of a few insurance and frienclly society agents.

The first certificates were a great nuisance, as they were far too elaborate. Those at present in use are easier, and on the whole satisfactory, but I think it is a pity that all the approved societies do not fall into line and have a uniform card made to last twenty-six weeks. This could easily be initialled by the practitioner, and he would be saved writing out the name of the person and his or her disease on a fresh continuation certificate cach week.

One society, the North-Eastern Railway Serrants' Pension Society, would easily carry off the prize if ons were offered for the most complicated certificate ingenuity could devise.

I occasionally hear of complaints, and my attention has been twice drawn to charges made against, panel men by the highly virtuous editor of a certain weekly paper, but even if a case of neglect here and there be substantiated, the general public should remember that eren doctors ano only human. It is so easy for a lay person to forget that a doctor is not a machine. A few years of practice soon teach us that the great majority of these scarc messages are quite trivial, and after a hard day's work, precedec probably by a very disturbed night, one can understand a man hesitating to turn out at midnight to see a patient who has probably been already ill several days, only to find when he arrives at the person's home that the case is not by any means urgent, and to be told that the patient was really much worse yesterday.

I took the trouble to investigate one case in which a man thought he had a grievance against his doctor. It appeared that this man had been treated by his doctor for', a "cold in the throat." As he did not get better quickly enough to please himself, he went to another doctor, who told him that he had " chronic subjection of the lungs," and that " pewmonia" was threatened. Truly a pitiful condition! I am happily able to tell you that the "pewmonia" was successfully arrested, and that the condition of the lungs is now in complete "subjection."

In the opinion of some people, the Insurance Act is not solely intended for sickness and unemployment benefit. A colleague of mine related to me an experience of his which bears out this statement. One Sunday evening he was told that a patient was waiting to see him in his consulting-room. On going there he found a man, who informed him that he was a panel patient. On my colleague remonstrating with him for coming on a Sunday, the man replied that he did not want medicine, but he wanted the loan of half a sovereign to bail out his brother. who had been " run in" the night before.

My experience of the maternity benefit is good. When the woman gets the money-and, like most of our wives, she usually takes good care of that-it must be of the greatest possible help to her.

Sanatorium benefit is yet in its infancy, but when the sanatoriums necessary are all built (and hearen alone knows when that will be), and if such able men are in control as we have in this district, the advantages must be enormous.

The position of the deposit contributor is shamefully pitiful. A private patient of mine contracted acute rheumatism in December, 1912. This was afterwards complicated by a double pneumonia, and he becarne a panel patient in January, 1913. In April I asked him if he were drawing his sick pay regularly. He told me he had applied for it, but he found that, owing to deductions, the total sum standing to his credit was only 10s. $8 \mathrm{~d}$. And he had become a deposit contributor because he thought the Government safer than any approved society. 
On the whole, I think in this district the Act, so far as the medical part is concerned, is now working smoothly, and the fact that during the whole of 1913 it was only necessary to call one meeting of the Medical Service Subcommittee, and that for the purpose of electing a chairman, speaks for itself. This state of things is largely due to the amiable relations that have always existed between the Local Medical and the Insurance Com. mittees. I consider we owe a debt of gratitude, on the medical side, to Dr. Don and $\mathrm{Mr}$. Willan and the other members of the Local Medical Committee, and on the lay side, to Mr. Stableforth, Mr. Schultz, and the Insurance Committee as a whole, for the excellent work done, during a trying time, in our interests. The Insurance Committee has always endeavoured to meet our expressed wishes, to help us in our difficulties, and last, but not least, has been most punctual in its payments to us.

There is one arrangement under the Act to which the committee quite willingly agreed which is deserving of all praise-I refer to the limiting of consulting hours to 9 to 9.30 a.m. and 6 to 7 p.m. I appreciate the 7 o'clock limit most. The sonatas of Beethoven are delightful; the music of Schubert is charming; the musical cadence in Grinling's voice when reciting his own poetry, and in Campbell's when, with exquisite pathos, he sends it reverberating among the "Mountains of Morne," cannot be denied; the booming sonoronsness of Russell is a thing to be remembered ; but there is nothing so pleasing to my ear, so full of a nameless charm, so wholesome and refreshing, as the sound of my hall clock striking 7 .

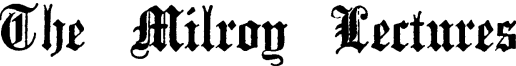

\section{THE HYGIENIC ASPECT OF THE COAL- MINING INDUSTRY IN THE UNITED KINGDOM.}

Delivered before the Royal College of Physicians of London.

BY FRANK SHUFFLEBOTHAM, M.A., M.D.C.AnTaB., J.P.,

MEDICAL REFEREE UNDER THE WORKMEN'S COMPENSATION ACT FOR THE NORTH STAFFORDSHIRE DISTRICT.

LECTURE IV.

MINERS' NYSTAGMUS.

Miners' nystagmus must be regarded as the commonest of all occupational diseases. This may be due to the fact that the mining industry is, after agriculture, the largest industry in the country. In my opinion the number of cases of miners' nystagmus far exceeds the numbers which would be given in compensation statistics, which take account only of cases in which undoubted incapacity for work has been produced, and not of the much larger numbers of early cases in which the patients are able to continue in their employment.

This disease was first recognized by Gillett of Sheffield about 1854 , although no case was mentioned in medical literature until 1861, when the symptoms were described by de Conde, a Belgian physician. Cases were reported by Pepp Müller as early as 1860, by von Graefe in 1873, and by Bell Taylor of Nottingham and by Neiden in 1874. In this country we are indebted to a very large extent to the observations and writings of the late Simeon Snell and for his pioneer work on this manysided disease: in France, Dransart occupies a similar position.

The disease is now recognized in this country and in all the principal coal-mining countries as a disease affecting the earning capacity of coal-miners, and in 1907 it was scheduled as an occupational disease under the Workmen's Compensation Act in order to entitle sufferers to compensation.

Frequency of the Disease.

Dr. Court has stated, as a result of the examination of sereral thousands of workmen, that 35 per cent. of coal. getters are subject to this disease to some extent, Snell estimated that 5 per cent. of all colliery workers were affected, but he did not discriminate between different kinds of work in the coal pit. Nieden, who examined nearly 30,000 coal-miners, agrees with Snell that the frequency of nystagmus in underground workers is some where about 5 per cent. In the North of France, Dransart and Famechon have given $10 \mathrm{per}$ cent. as the number affected. Romiee and Thibert of Liége during 1908 and 1910 examined 5,000 workmen in twenty-seven collieries. More than three-fifths were coal-getters, and on the average 21 per cent. were affected with symptoms of nystagmus; in collieries lighted by lamps burning heavy oils 37 per cent. of the coal-getters were affected. Romieo had made a similar inquiry in the same district in the years 1877-8, and the result of his later inquiry was to show a marked diminution in the number of cases as well as in the severity of the symptoms. Stassen, who in 1909 examined 3,385 colliers descending into the pit, and also on their return to the surface, found that 15 per cent. of the workers were affected before commencing thei work, and 22 per cent. at the end of the shift.

Roger of Hondeng-Geognies, as a result of examining over 7,000 workmen, came to the conclusion that 17.5 per cent. were suffering from nystagmus. Libert, the Chief Inspector of Mines to the Belgian Government, found different percentages of miners affected in different districts. In one series of examinations which he con. ducted with the help of Romiee and Thibert he found that of 305 workmen examined in one pit 73 were affected with miners' nystagmus, giving a percentage of 23.9 , and he refers to a memoir dealing with 3,685 workmen, among whom 704 showed symptoms of this disease, or a percentage of 19.1. The following table gives details of the work and the frequency of nystagmus among the different classes of workers :

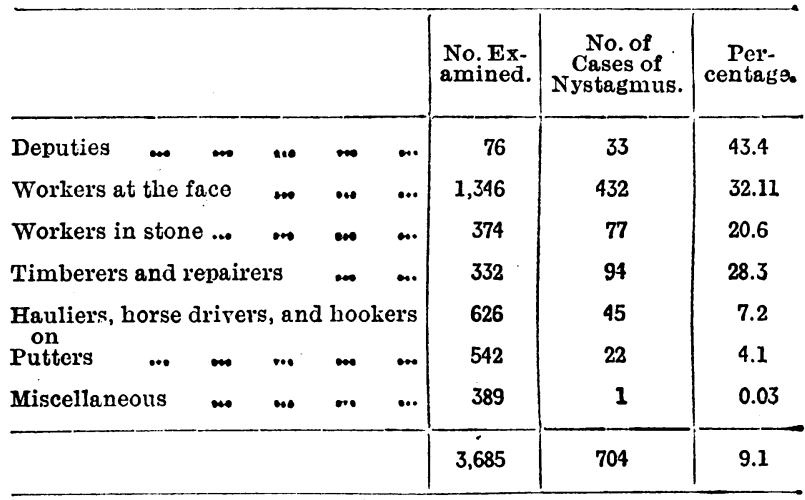

Nystagmus is almost unknown in ironstone and metalliferous mines, and in naked-light pits from which coal is obtained it is very much less frequent than in mines in which safety lamps are used. In two naked-light colliery districts in which over 12,000 underground workmen were employed, Llewellyn records that there was only one known case of miners' nystagmus. This, however, may be accounted for by the fact that this was the only case for which compensation was paid, and a systematic examination of the men would probably reveal that many more workers were affected.

Llewellyn, as a result of careful examination of 173 officials, chiefly firemen, foumd that 61 , or 35.2 per cent. were affected with nystagmus of a latent type. He draws a distinction between the grave types of this disease and the milder types which he calls "latent," and the same classification has been made by Dransart and Famechon.

Symptoms of nystagmus are most commonly found among miners engaged in holing, a process which consists of cutting the coal seam so as to get out the coal in pieces as large as possible. The holer lies on his side with his knees drawn up and his head thrown backwards, and he strikes the coal with a horizontal swing, the lamp being placed near his feet. He may undercut the searn or "top cut" it, but in either case the muscles of the eyeballs are continually in a strained position, generally in an upward or oblique direction. As a result of this eyestrain the elevator muscles suffer from strain and cramp. Similar effects are found in other muscles, producing wry-neck, twitching of the eyelids, and tremors of the head. Holers 